\title{
International experiences with co-production and people centredness offer lessons for covid-19 responses
}

\author{
Eva Turk and colleagues believe that there is much to learn from the experiences of low and \\ middle income countries in co-producing knowledge and working with communities to find feasible \\ and acceptable solutions to healthcare concerns
}

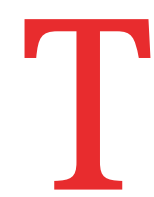
he development and implementation of health policies and interventions must be done with, and not simply done to, the people affected. Collaborative healthcare requires engaging with individuals and communities using models of care that are patient centred. These models are informed, rather than dictated, by scientific knowledge that might or might not apply to an individual patient and their circumstances. ${ }^{1}$ Collaboration allows patients, user groups, and communities to assert some control over delivery of their care and hold health providers to account. Given the uncertainty and mistrust about how best to deal with the covid-19 pandemic, collaboration is more important than ever.

Co-production of healthcare can take place throughout the health system, ranging from governments working with patient organisations, to health facilities involving patient representatives, to the clinical meeting between a health

\section{KEY MESSAGES}

- For too long, health research and the development of health policies and interventions have been done to, and not with, communities and individuals, often leading to failure

- The covid-19 pandemic has shown the importance of strengthening the co-production of health research and provision of health services by embedding a people centred approach at all levels of healthcare in all countries

- To build back better, researchers and policy makers need to rethink how to involve communities in co-production of research, knowledge, and health systems

- Power dynamics between different groups create barriers that must be dealt with if progress is to be made professional and a patient. ${ }^{2}$ Put simply, it involves "getting everybody around the table so you are valuing everyone's knowledge."3 It demands building a shared understanding between researchers, policy makers, practitioners, and managers, as well as patients and their families, and working together to improve quality and care.

While there should be little disagreement that co-production is a good idea, it does need a supportive culture and regulatory framework, with organisational structures and procedures in place. ${ }^{45}$ It also requires acceptance of the need to share power, take account of each other's perspectives and skills, respect and value different types of knowledge, and commit to building and maintaining the relationships within the collaboration process. Co-production is therefore a dynamic and often complex process in which information, resources, timescales, and people are continually changing. $^{67}$

Co-production is increasingly used within health research, building on methods such as participatory research, engaged scholarship, collaborative research, and integrated knowledge translation. ${ }^{89}$ We see it as occurring where researchers work in partnership with knowledge users, comprising patients and care givers, clinicians, policy makers, health system leaders, the public, and others, to identify a problem and produce a solution, sharing power and responsibility throughout the research. ${ }^{10}$ Consequently, co-production in health research overlaps with its application in healthcare provision. Both focus on improving quality, whether of health research, policies, or interventions, in order to increase acceptance and uptake of healthcare by end users.

\section{Co-production places patients at the centre}

The involvement of communities in the coproduction of research and the provision of health services can improve health and wellbeing and make policy initiatives more sustainable. ${ }^{11-13}$ By embedding principles of equity, dignity, respect, and trust in communication among different stakeholders, co-production can also enhance the accountability and person centredness of health systems. ${ }^{14}$

Application of these principles to the design of people centred health systems can take different forms. Coulter and colleagues, in the "house of care," seek to co-produce health based on a conversation between clinicians and patients. ${ }^{15}$ Wagner's chronic care model and the World Health Organization framework on integrated, people centred health services also emphasise the importance of patients working with health professionals to improve functional and clinical outcomes. Such processes must also be supported by appropriate resources and policies. ${ }^{1617}$ Others describe a co-produced healthcare service in which patients and professionals interact as participants within health systems. $^{18}$

Our experiences in low and middle income countries show how co-production challenges the traditional roles of health professionals and researchers, which are often based on long established imbalances of power. Co-production is not always easy, but to achieve community participation in health research and practice, we must overcome barriers created by existing hierarchies. ${ }^{19}$

In Peru, researchers, health workers, and policy makers, working with communities, co-produced interventions to improve diagnosis and management of chronic diseases in rural areas as part of the COmmunity HEalth System InnovatiON (COHESION) project. ${ }^{2021}$ They developed a package that included radio programmes to help improve health literacy among patients, and interventions, such as training for health workers and 
infrastructure improvements. Because the local measures were embedded within a national framework, they worked at all levels of the health system, supported by a national advisory group. Patients and healthcare providers were each provided with a safe space to identify and discuss their own concerns and priorities. The groups then joined together to find shared solutions, which included jointly selecting and prioritising interventions. The collaboration process supported patients and health providers in finding sustainable and acceptable solutions to improve the diagnosis and management of chronic diseases. The process did have its challenges, however, such as managing the expectations and requirements of the community while following best scientific practice. To develop the package, the different stakeholders also had to interact regularly, which occupied more of people's time and resources than other approaches. $^{20}$

Co-production requires transparency and accountability to achieve the mutual trust that is sometimes lacking within health systems. ${ }^{22}$ Consultation with health service users requires methods that are more than just a token. If service users are to have a measurable effect on social, health, and service outcomes, there must be a real sharing of power. ${ }^{2324}$ For example, the Nigeria Centre for Disease Control established a covid-19 research consortium to strengthen the involvement of stakeholders in the co-production of research. Researchers, policy makers, and representatives of those on the front line of the covid-19 response collaborated to define national research priorities, map existing resources, and develop and implement a long term programme for research-the Nigeria covid-19 research plan, 2020-4. ${ }^{25}$

In Tanzania, health facility governing committees have been established in district hospitals, health centres, and dispensaries to increase transparency and accountability for the planning and provision of healthcare. These committees offer a way for communities and patients to be involved in decision making so that health services become more responsive to their needs. ${ }^{26}$ Facilities have developed new ways of including the most marginalised groups-for example, by providing appropriate face to face health education for community members with low levels of literacy. Although the committees have created a sense of ownership and acceptance of decisions within communities, their future faces resource constraints, including low educational levels among committee members and inadequate funds. ${ }^{27}$

\section{Strengthening inclusivity in the co-production of knowledge}

We should not minimise the substantial challenges to adopting a co-production approach or the shift in thinking it requires. ${ }^{28}$ Although the co-production of health research is increasing, it has a long way to go. A systematic review of community participation in health systems research identified 260 papers with more than nominal community participation in the research described. In $95 \%$ of papers, communities helped in implementing an intervention but were involved in identifying and defining problems in only $18 \%$ of articles. ${ }^{29}$ Only five papers discussed power imbalances. Overall, the literature showed little recognition of the many problems that can influence a community's participation in the co-production of research and models of care, including power relations, prevailing knowledge, and beliefs and cultural barriers.

Those responsible for planning, developing, and implementing acceptable health services must adopt an inclusive approach to the construction of knowledge. This approach requires a move away from the dominant supply driven modes of knowledge, "push," to an approach that emphasises demand, "pull," where services are effectively tailored and targeted. Such an approach, however, can place competing pressures on the time and capacity of patients and providers to participate, and highlights the need for appropriate structures. ${ }^{30-32}$

Failure to co-produce knowledge also has a cost. For example, the Nigerian government developed a national risk communication campaign, 'Take Responsibility', to increase covid-19 awareness within the population. ${ }^{33}$ It soon became clear, however, that the initial messaging, developed by officials and disseminated in a top down fashion, was not appropriate because it did not deal with differences such as literacy, language, and other sociocultural variations. This messaging was replaced by a process of community engagement to understand people's fears and beliefs and which supported communities to work with risk communication officers and trained state health educators to co-develop their own risk communication messages and dissemination strategies. Focus group discussions and audio diagnosis (providing feedback and ensuring understanding of audiovisual communication materials) were used to develop and assess jingles, role play, animations, infographics, and messages to be conveyed by town criers. Images depicted key health promotion messages, such as people standing with horizontally outstretched arms to convey two metres distance, and content was translated into local languages. Polling results showed that within 12 weeks of implementing these new strategies in Lagos, an increase of $22 \%$ occurred (from $59 \%$ to $81 \%$ ) in the proportion of the population that considered covid-19 to be real and not a hoax. ${ }^{34}$

If co-production is to be truly transformative, there must be a shift of power towards patients and communities. New types of relationship must be developed between patients, health professionals, and researchers, supported by political commitment. ${ }^{35}$ We know such transformation is not easy so it is perhaps unsurprising that a recent systematic review of primary care interventions for non-communicable disease found that even when the terminology of co-production is used there is little connection between local community priorities and interventions implemented. ${ }^{36}$ The Ebola outbreak in west and central Africa exemplified the misunderstandings and distrust that can arise when priorities and solutions are imposed on local communities. ${ }^{37}$ Social scientists identified many situations where researchers and policy advisers understood the situation differently from the local populations. ${ }^{38}$ When researchers did engage effectively with patients and frontline health workers in the development of health services and conduct of research, popular fears about treatment centres were allayed and public trust grew. The anthropologist Paul Richards has written a detailed account of how researchers and local communities worked together to find solutions that were both practical and acceptable as they gained what he called "merged understanding." 3739

Similarly, during the covid-19 pandemic, governments and health authorities in many countries have repeatedly imposed top down measures, which, while informed by research, often took little account of the communities affected. ${ }^{40}$ Developing covid19 measures that are feasible and practical is crucial, as is understanding what communities value and need in times of crisis. Such measures will not be achieved 
unless communities are encouraged and enabled to become active partners in research and the provision of healthcare. It requires the support of governments and imaginative solutions by all stakeholders. The Social Science in Humanitarian Action Platform shows why it is important for patients and communities to be at the centre of co-production approaches during emergency responses. ${ }^{41}$

\section{Looking forward}

Covid-19 offers an exceptional opportunity to strengthen the co-production of health research and provision of health services by embedding a people centred approach in all levels of healthcare. Solutions to health problems can be found when patients with lived experiences, their families, and communities come together with researchers, health professionals, and decision makers to co-produce knowledge. A co-production approach would make it possible to build back better after the pandemic with more resilient health systems that focus on what people need.

Partnerships between researchers, practitioners, and policy makers in health research and practice are morally right and, at least when adequately supported, can work. However, co-production can place additional burdens, both financial and temporal, on those involved, and might not always be feasible. Even when structures are put in place to support co-production and promote person centredness and accountability, power imbalances can remain. Overcoming barriers to engagement by all requires understanding the dynamics of intergroup relationships, and recognising, and dealing with, the inequitable distribution of social, economic, and political resources among stakeholders within the co-production process. ${ }^{42}$ Only then can there be a shift of power towards patients and communities which allows for the identification of community priorities and the co-production of relevant research and healthcare in response to their needs.

We need more research on the critical factors that enable co-production to deliver effective, accountable, and people centred health services. ${ }^{19}$ We also require a better understanding of the often opaque power imbalances and competing incentives, including nepotism and corruption, that characterise some decision making in health. ${ }^{43}$

Co-production in health research and practice offers a means to shift from "sick care," and a focus on disease, to "people centred care,” and a focus on people.
Putting patients at the centre of their care, is not a panacea and will not always lead to perfect processes, but it is surely a necessary and welcome step towards more equitable, accountable, and resilient health systems.

This research is supported by the Singapore Ministry of Health's National Medical Research Council under the Singapore Population Health Improvement Centre (NMRC/CG/C026/2017_NUHS).

Contributors and sources:. ET, AD-B, EH, SB, SR, MM, and $\mathrm{HL}-\mathrm{Q}$ drafted the manuscript. MMML, CO, MLP, PM, and GF contributed the case studies. All authors contributed to revising the manuscript. ET and AD-B are joint first authors. HL-Q is the guarantor.

Competing interests: All authors have read and understood BMJ policy on declaration of interests and have no interests to declare.

Provenance and peer review: Commissioned; externally peer reviewed.

This article is part of a series produced in conjunction with the WHO and the Alliance for Health Policy Systems and Research with funding from the Doris Duke Charitable Foundation. The BM/ peer reviewed, edited, and made the decision to publish.

Eva Turk, associate professor ${ }^{1,2}$

Anna Durrance-Bagale, research fellow ${ }^{3}$

Emeline Han, research associate ${ }^{4}$

Sadie Bell, research fellow ${ }^{3}$

Selina Rajan, research fellow ${ }^{3}$

Maria Margarita M Lota, assistant professor

Chinwe Ochu, head

Maria Lazo Porras, research associate ${ }^{7}$

Pallavi Mishra, senior research fellow ${ }^{8}$

Gasto Frumence, associate professor ${ }^{9}$

Martin McKee, professor $^{3}$

Helena Legido-Quigley, associate professor ${ }^{3,4}$

${ }^{1}$ Science Centre Health and Technology, University of South-Eastern Norway, Drammen, Norway

${ }^{2}$ University of Maribor, Faculty of Medicine, Maribor, Slovenia

${ }^{3}$ London School of Hygiene and Tropical Medicine, London, UK

${ }^{4}$ Saw Swee Hock School of Public Health, National University of Singapore and National University Health System, Singapore

${ }^{5}$ Department of Medical Microbiology, College of Public Health, University of the Philippines, SEAMEO TROPMED Regional Center for PUBLIC Health, Hospital Administration, Environmental and Occupational Health, Manila, Philippines

${ }^{6}$ Prevention, Programmes and Knowledge Management, Nigeria Centre for Disease Control, Abuja, Nigeria

Universidad Peruana Cayetano Heredia, Lima, Peru ${ }^{8}$ Centre for Chronic Disease Control, New Delhi, India

${ }^{9}$ School of Public Health and Social Sciences, Department of Development Studies, Muhimbili University of Health and Allied Sciences, Tanzania Correspondence to: Martin McKee Martin.mckee@lshtm.ac.uk

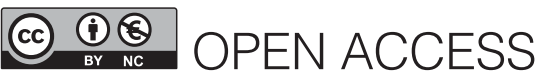

This is an Open Access article distributed under the terms of the Creative Commons Attribution IGO License (https://creativecommons.org/licenses/ by-nc/3.0/igo/), which permits use, distribution, and reproduction for non-commercial purposes in any medium, provided the original work is properly cited.

\section{Check for updates}

1 McCormack B, van Dulmen S, Eide H, et al. eds. Person-centred healthcare research. John Wiley \& Sons, 2017, doi:10.1002/9781119099635

2 Vennik FD, van de Bovenkamp HM, Putters K, et al. Co-production in healthcare: rhetoric and practice. Int Rev Adm Sci 2016:82:150-68. doi:10.1177/0020852315570553

3 Coldham T. Meet the co-pro maestro. 2018. https:// www.nature.com/articles/d41586-018-06926-9.

4 Kleintjes S, Lund C, Swartz L, Flisher A, The Mhapp Research Programme Consortium. Mental health care user participation in mental health policy development and implementation in South Africa. Int Rev Psychiatry 2010:22:568-77. doi:10.3109/0954 0261.2010 .536153

5 Rutter D, Manley C, Weaver T, Crawford MJ, Fulop N. Patients or partners? Case studies of user involvement in the planning and delivery of adult mental health services in London. Soc Sci Med 2004;58:1973-84. doi:10.1016/S0277-9536(03)00401-5

6 Rasmussen E, Jørgensen K, Leyshon S. Personcentred care: co-creating a healthcare sector for the future: DNV GL 2014.

7 Hickey G, Brearley S, Coldham T, et al. Guidance on co-producing a research project. Involve 2018. https://www.invo.org.uk/wp-content/ uploads/2019/04/Copro Guidance Feb19.pdf

8 Beresford P. Public participation in health and social care: exploring the co-production of knowledge. Frontiers in Sociology 2019;3:41. doi:10.3389/ fsoc. 2018.00041

9 Langley J, Wolstenholme D, Cooke J. 'Collective making' as knowledge mobilisation: the contribution of participatory design in the co-creation of knowledge in healthcare. BMC Health Serv Res 2018;18:585. doi:10.1186/s12913-018-3397-y

10 Kothari A, McCutcheon C, Graham ID. Defining integrated knowledge translation and moving forward: a response to recent commentaries. Int J Health Policy Manag 2017;6:299-300. doi:10.15171/ijhpm.2017.15

11 Gillies P. Effectiveness of alliances and partnerships for health promotion. Health Promot Int 1998;13:99 120. doi:10.1093/heapro/13.2.99

12 Rifkin SB, Hundt GL, Draper A. Participatory approaches in health promotion and health planning: a literature review: summary bulletin. Heath Development Agency, 2000. https://www.academia.edu/26421309/ Participatory Approaches in Health Promotion and Health_Planning_a_Literature_Review

13 Wallerstein N. What is the evidence on effectiveness of empowerment to improve health? WHO Regional Office for Europe, 2006:37. https://www.euro.who. int/ data/assets/pdf file/0010/74656/E88086.pdf

14 Legido-Quigley H, Asgari-Jirhandeh N. Resilient and people-centred health systems: progress, challenges and future directions in Asia. 2018. https://apps.who.int/iris/bitstream/hand le/10665/276045/9789290226932-eng. PDF? sequence $=5$ \&isAllowed $=y$

15 Coulter A, Roberts S, Dixon A. Delivering better services for people with long-term conditions. Building the house of care London. King's Fund, 2013:1-28. https://www.kingsfund.org.uk/sites/default/files/ field/field publication file/delivering-better-servicesfor-people-with-long-term-conditions.pdf

16 Wagner EH. Chronic disease management: what will it take to improve care for chronic illness? Eff Clin Pract 1998;1:2-4.

17 Barr VJ, Robinson S, Marin-Link B, et al. The expanded Chronic Care Model: an integration of concepts and strategies from population health promotion and the Chronic Care Model. Hosp Q 2003;7:73-82. doi:10.12927/hcq.2003.16763 
18 Batalden M, Batalden P, Margolis P, et al. Coproduction of healthcare service. BMJ Qual Saf 2016;25:509-17. doi:10.1136/bmjqs-2015-004315

19 Haldane V, Singh SR, Srivastava A, et al. Community involvement in the development and implementation of chronic condition programmes across the continuum of care in high- and uppermiddle income countries: a systematic review. Health Policy 2020;124:419-37. doi:10.1016/j. healthpol.2019.11.012

20 Lazo-Porras M, Perez-Leon S, Cardenas MK, et al. Lessons learned about co-creation: developing a complex intervention in rural Peru. Glob Health Action 2020;13:1754016. doi:10.1080/16549716 2020.1754016

21 COHESION project. 2016. https://cohesionproject. info/.

22 Sheahan M, Little R, Leggat SG. Performance reporting for consumers: issues for the Australian private hospital sector. Aust New Zealand Health Policy 2007;4:5. doi:10.1186/1743-8462-4-5

23 O'Mara-Eves A, Brunton G, McDaid G, et al. Community engagement to reduce inequalities in health: a systematic review, meta-analysis and economic analysis. Public Health Research 2013;1(4). https://www.ncbi.nlm.nih.gov/books/ NBK262817/

24 Popay J. Community engagement for health improvement: questions of definition, outcomes and evaluation. A background paper prepared for NICE. NICE, 2006

25 Nigeria COVID-19 Research Consortium (NCRC) www.ncrc.org.ng

26 United Republic of Tanzania. A model instrument for establishment of council health service board. Under section 86A of Act No 7, 1982. In: Government PMORALG, ed. Dar es Salaam, 2001

27 Frumence G, Nyamhanga T, Mwangu M, Hurtig AK. Participation in health planning in a decentralised health system: experiences from facility governing committees in the Kongwa district of Tanzania. Glob Public Health 2014;9:1125-38. doi:10.1080/1744 1692.2014.953563

28 Oliver K, Kothari A, Mays N. The dark side of coproduction: do the costs outweigh the benefits for health research?Health Res Policy Syst 2019;17:33. doi:10.1186/s12961-019-0432-3

29 George AS, Mehra V, Scott K, Sriram V. Community participation in health systems research: a systematic review assessing the state of research, the nature of interventions involved and the features of engagement with communities. PLOS One 2015;10:e0141091. doi:10.1371/journal. pone.0141091

30 Kirchhoff C), Carmen Lemos M, Dessai S. Actionable knowledge for environmental decision making: broadening the usability of climate science. Annu Rev Environ Resour 2013;38:393-414. doi:10.1146/ annurev-environ-022112-112828

31 Roux DJ, Rogers KH, Biggs HC, et al. Bridging the science-management divide: moving from unidirectional knowledge transfer to knowledge interfacing and sharing. Ecol Soc 2006;11. https://pdfs.semanticscholar.org/3b20/360 ec9adada79370983d03f4d44a5e218740. pdf?_ga=2.162384763.632428784.1607604394508401373.1607604394. doi:10.5751/ES01643-110104

32 Vincent K, Daly M, Scannell C, et al. What can climate services learn from theory and practice of co-production?Clim Serv 2018;12:48-58. doi:10.1016/j.cliser.2018.11.001

33 Nigeria Centre for Disease Control. https:// covid19. ncdc.gov.ng/resource/.

34 Ochu C, Akande O, Ihekweazu V, et al. Responding to a pandemic through socio-behavioural change communication: Nigeria's experience. Health Secur (forthcoming). doi:10.1089/hs.2020.0151
35 Realpe A, Wallace LM. What is co-production. The Health Foundation, 2010

36 Liu H, Mohammed A, Shanthosh J, et al. Process evaluations of primary care interventions addressing chronic disease: a systematic review. BMJ Open 2019;9:e025127. doi:10.1136/ bmjopen-2018-025127

37 Richards P, Mokuwa E, Welmers P, Maat H, Beisel U. Trust, and distrust, of Ebola treatment centers: s case-study from Sierra Leone. PLoS One 2019;14:e0224511. doi:10.1371/journal. pone. 0224511

38 Wilkinson A, Parker M, Martineau F, Leach M Engaging 'communities': anthropological insights from the West African Ebola epidemic. Philos Trans R Soc Lond B Biol Sci 2017;372:20160305. doi:10.1098/rstb.2016.0305

39 Richards P. Ebola: how a people's science helped end an epidemic. Zed Books Ltd, 2016.

40 Gilmore B, Ndejjo R, Tchetchia A, et al. Community engagement for COVID-19 prevention and control: a rapid evidence synthesis. BMJ Glob Health 2020;5:e003188. doi:10.1136/ bmjgh-2020-003188

41 Social science in humanitarian action platform. https://www.socialscienceinaction.org/about.

42 Balane MA, Palafox B, Palileo-Villanueva LM, McKee M, Balabanova D. Enhancing the use of stakeholder analysis for policy implementation research: towards a novel framing and operationalised measures. BMI Glob Health 2020:5:e002661. doi:10.1136/bmjgh-2020-00266143 E Hutchinson D, Balabanova M McKee. We need to talk about corruption in health systems. Int Health Policy Manag2019;8:191-4. doi:10.15171/ ijhpm.2018.123 31050963

Cite this as: $B M / 2021 ; 372: \mathrm{m} 4752$

http://dx.doi.org/10.1136/bmj.m4752 